Proceedings

\title{
For a Philosophy of Representation `
}

\author{
Raffaele Milani \\ Department of Education Studies “Giovanni Maria Bertin”, University of Bologna, 40126 Bologna, Italy; \\ raffaele.milani@unibo.it \\ + Presented at the International and Interdisciplinary Conference IMMAGINI? Image and Imagination \\ between Representation, Communication, Education and Psychology, Brixen, Italy, 27-28 November 2017.
}

Published: 22 December 2017

\begin{abstract}
We often wonder if aesthetics cannot be considered to be a philosophy of representation since it concerns itself with reality splitting in the images of the imagination, and with the distinction between the contemplative gaze and the nature of aesthesis (perception with all the senses). For this reason, an attempt is made here to shed light upon the "neutral horizon" of beauty without excluding the living part of things and feelings. Our point of departure is the experience of art taking note of the creativity of the aesthetic response once we interpret the "death of art" in the modern world not as an actual end but as an opening up of a plethora of evocative, perceptual, and formative features. In light of the artworks of the last decades, non-narrative films, Environmental Art and Land Art, repetitive music, and deconstructionist architecture, we might well wonder what remains of art, beyond beauty, and what remains of beauty, beyond art. Only an image, perhaps? In addition, with respect to these epochal transformations, the concept of body has been transformed. It is no longer a container; it has become liquefied and has become an attitude. What emerges is either anguish or enthusiasm in the face of these changes, depending on one's point of view.
\end{abstract}

Keywords: philosophy; iconology; representation; imagination

The term representation can be understood in either the subjective or objective sense. In the first use, representation is taken to mean the capacity of consciousness to visualize something, both an external object and a state of mind, as an object within itself; in the second, the representation is the immediate object of awareness in that it is represented or made present to consciousness. Both the act and the fact of representation, although more so the former than the latter, can be studied from both a philosophical and a psychological point of view, depending on whether we consider the capacity of consciousness to place something before itself as an object and the mode of this activity, on the one hand, or the mechanism of this function of consciousness, notwithstanding the relationships between subject and object and the nature of that object, on the other hand. The first aspect is essentially gnoseological; in fact, it pertains to the essence of the problem of knowledge in that it concerns precisely the possibility and modes of knowledge. However, since in discussing knowledge, which necessarily implies two terms, the knower and the known, we cannot do without analyzing the nature of the known relative to the knower, we have to extend the study of representation into metaphysics. The three possible solutions to the metaphysical problem entail three different approaches to the gnoseological question: (a) the skeptical approach, in which the nature of the represented object is unknowable and its existence problematic due to the absolute absence of a guarantee that there exists a correspondence between the representation and the object represented, thereby denying the gnoseological problem as well, or declares it to be unsolvable; (b) the realist approach which, by asserting the existence of the real object independently of any action on the part of the subject, concentrates the study of representation on the relationships between subject and object, and inspires a vast array of viewpoints, ranging from blind faith in the absolute correspondence between the representation and the real object to a sort of gnoseological skepticism, 
according to which the representation of the object as it actually exists is impossible, and thus the realist approach becomes phenomenological; (c) finally, the idealist approach, which denies all distinctions between subject and object, between being and thought, and considers thought to be the producer of being, and in so doing, rather than frame the gnoseological problem differently, confuses it with the realm of metaphysics and, inasmuch as it makes the represented object a product of the activity of representation, it eliminates as well the above distinction between the subjective and the objective meaning of the term representation.

The ancients were familiar with this term and, as we see in Plato, they considered representation as a mirror image of sensible objects (the Republic) and then distinguished between true and false images, which either resemble the reproduced image or not (the Sophist), that is to say, whether they are representations or products of the imagination. Aristotle and later Aquinas continued to debate this issue. In modern philosophy the meaning of the term undergoes a profound change as the focus shifts from the object to the subject. We should not, however, forget the ancients. For example, on the issue of the pedagogy of "typical" images, Plato's teaching is still valid, and one of his most recent interpreters, Jean-Jacques Wunenburger [1], contends that the Greek philosopher allowed, under certain conditions, a pathway to the truth. He identifies there a "typos" that permits us to recover the hidden relation between the copy and the model. In the plastic arts the "typos" is the mould or the stamp, and in the metaphorical pedagogical context it becomes an imprint left by the Ideas on the human soul, which guarantees a sort of fidelity between the original and the copy. In fact, some passages of the Dialogues seem to allow a dynamic connection between image and essence. The perceptual experience of some images, especially artistic ones, reawakens in us a hidden sense that leads us from the image to its raison d'être. In other words, in perceptual experience, the objective dissimilarity of the image, even in the case of mythic tales or visual representation, is not incompatible with an anagogic function that allows it to return to the essential source of the thing represented without being entrapped by false conceptions. In other words, the illusory quality of the allegorical image (for instance, in the allegory of the cave described in the Republic) is displaced by an autoreferential search for its original model since every soul is potentially open to the truth that lies dormant within it. Wunenburger contends that the Platonic concept of "typos", starting with the prisoner's release from the cave, initiates an alternative, less iconoclastic, approach to the question of first principles, which allows some souls to penetrate the images and attain their essence without, in so doing, getting lost in optical illusions that are harmful to consciousness. In this sense, training in the appreciation of beauty can be preparatory in certain arts, such as music and poetry, and constitutes stages in an ascent that allows us to go from the idol to the icon and from the icon to true essence. We might say, along with Wunenburger, that there are two poles in Plato's teachings: on the one hand, pure form, intuitive knowledge free of language, and the image of essences, which is more implied than described, and, on the other hand, an impure form linked to artistic praxis, artificial representations, and deceitful words in a city inhabited by sophists and poets. In some respects, we find this same situation in today's society of simulation, spectacle, mechanical reproduction, and mass-media images. Between these two poles, however, there is an intermediate world, namely, the aesthetic (or artistic) one, which we occupy. We discover that we are living in a mixed, uncertain, ambivalent ekphrasis where fictions abound. On the one hand, contents are animated and touch the spirit, making it feel as though it is in direct contact with things, and visual images are restored to their tipoi; on the other hand, the images evoke a return to the philosophical ideal of ultimate understanding of essential truth. From the visibility of the invisible that eludes the control of the idola, we move to the simulation and illusion of the original. We inhabit a place of crossings, where we find intersections of language and visual representation. It may be a non-place of truth, but a necessary and pleasant one.

From these observation based on a philosophy of representation, the image cannot be merely a form of mirroring.

We now proceed from this general observation and enter into the details of our analysis. It is said that a living thing participates in infinity; each of us has something of the infinite within. We cannot fully comprehend this notion of the existence of the living being in the process of achieving 
perfection, or even the more limited sense, without placing it in the immense whole in which all existence unfolds. We perceive and tangibly make our own and imagine what is common to us as beings. But in what forms of representing does our mind engage? The artistic, scientific, and technological universe exhibits a level similar, or apparently similar, to that of humanity as it evolves, and we learn that the notion of "formation energy" plays an important role. From the expansion of that energy stems the impression that the totality of nature cannot be captured by observing a single object within the whole, that the cognitive clarity of reason, the proliferating representation, or the mirroring produced in the most limpid way by external senses are insufficient. All relationships existing in the great whole, intuited dimly, activated by energy in effect, must necessarily become visible, audible, or at any rate perceivable, by the imagination. In the course of history, the sense of infinity has been discussed in biology, philosophy, the natural sciences, and aesthetics. But how do we represent the individual thing within the whole? How do we imagine in the totality of living beings? How can we place the image in relation to representation, and the imagination in relation to the imaginary?

Jean-Paul Sartre [2-4] takes a phenomenological approach to solving a complex bundle of problems related to our topic. The central question has been with us since antiquity, but from seventeenth-century philosophy to the psychology of the first decades of the twentieth century, it becomes increasingly tangled. Needing to synthesize and to simplify, the question revolves around the connection between Eikasia (picture-thinking) and Phantasia (appearance), as well as around the many mental processes implicit in representation and the imagination. Sartre acknowledges that there is a good deal of ambiguity in our topic, an ambiguity that has led to a broad discussion on image-appearance, perception, the intellect, memory, consciousness, and freedom involving both sense and reason, the representable and the thinkable, meaning and phenomenon, subject and object. We, thus, have an ontology of the image where, as in a composite scenography, the spotlight shines on the panoramas of aesthetics and gnoseology. Framing our interpretation within Sartre's viewpoint, we must recognize, despite everything, the importance of this approach especially today, when the evolution of technology tends to bring about the loss of our sense of reality and to promote the exaltation of the imaginary world or simulation. Sartre sets Husserl's [5,6] principle of intentionality against the doctrines of associationism and experimentalism pursued by Alexander Bain, Wilhelm Wundt, and Theodule Ribot, and he interprets representation as an autonomous act capable of giving meaning to initial sense data. For Sartre [2-4], the imagination is consciousness and, as such, it cannot be considered to be merely a duplicating faculty. We are not dealing with a spectacle, within the conscious mind, of things that appear outside of it, but with the intention of consciousness directed toward a real object in a process of "derealization" of the external world. Unlike an empirical object, which can be sensed and perceived, an imagined object is (creatively) free. The imagination exists within the aura of unreflective or instinctive thought. In fact, things exist on two levels: one of presence, and one of images and absence. There is the naïve belief that simulacra and idols exist in themselves, just like the objects they stand for. Sartre [2-4] claims that most psychologists are confused by the theory of images formulated by Descartes, Spinoza, Leibniz, Hume, and Bergson. Image theory falls outside the theory of knowledge; these thinkers confuse essence and existence. Only Husserl [5,6] discerns the fact that perception and image are two intentional Erlebnisse (experiences of which one is cognizant) and that there is a distinction to be made between noesis (concrete psychic activity) and noema (the object or content of thinking). Intentionality is a noetic act, at the root of both the real world and the world of the imagination; it is active synthesis even in illusion, whereas perception is passive synthesis. Sartre expands on his views on consciousness in his writings of the second half of the 1930s. In essence, he is determined to avoid "reifying" the image and, at the same time, to steer phenomenologically clear of the illusion of immanence, and he invites us to do likewise. The image is "the incarnation of unreflective thought". It involves thought, but it is intuitive thought, which has an aura of unreality. For this reason, our attitude toward the image is radically different from our attitude toward things. It contains a magic, an enchantment, that causes the object or the thing desired to appear such that the mind can possess it. For Sartre, imaginary objects are mere passivity, lack, an empty stamp; their fragile nature derives from our spontaneity. 
The essential structure of the image is the absence of the entirely autonomous object, which we can access only by depersonalizing ourselves. I behave full conscious of the unreality of the object. Sartre goes on to exclude, or at any rate diminish, the role played by the will. For him, imaginary objects are short-lived and essentially independent of the will. These objects have a discontinuous, intermittent quality and do not provoke behaviours; they are quasi-sensible objects that (in a transcendental move) incorporate in the fabric of their representation, knowledge of the world, not a list of things. In these statements we hear the echo of Kant's theory of the free play of the imagination, but this is true only initially because for Sartre the image is the psychic energy we experience. This is a nihilistic energy that, from an aesthetic and creative perspective, can become something positive. In the imagination we can find once more the ambiguity of consciousness that is removed from both being and its own being and at the same time removed from the density of the world. This ambiguous knowing makes the aesthetic life fervid with its many, changeable forms. In the modern society of media, situated as it is between the real and the virtual, the world of images cannot be understood as a world in which nothing happens, as Sartre believes, but one in which the void reveals itself precisely thanks to the ludic uncertainty of the living being.

We now turn to the image of nature as it relates to representation and the will. Johann Wolfgang Goethe never used the phrase "morphology of natural beauty". It was John Ruskin who used the term after inheriting, whether he wanted to or not, the modes of seeing and contemplating typical of Goethe and his times. In our discussion on the images of the world and infinity, and simultaneously the images of the world and finitude, what is interesting is the fact that Goethe formulated the idea of a "formative force" and claimed that in inorganic nature nothing is in its primordial state. At the same time that Ruskin explored and posited his ideal of naturalism, Arthur Schopenhauer [7] confronted the same problem of the truth of nature through the notion of the unity of the body and the will. This is the key point in our reflection on the notion of thinking of the entire world as a sculpture and the living body, as opposed to Sartre who would go on to develop his dualistic view of the image. In Metafisica della natura [Metaphysics of nature], this body is given to the knowing subject in two different ways: as representation in the intuitive intellect, an object among other objects, subject to their laws, but also as will, something of which we have immediate and complete cognizance. Every act of the will is immediately and unfailingly also movement of the body; the subject cannot truly will an action without at the same time perceiving that, in representation, the action appears as the movement of its body. The action of the body is the action of the objectified will, that is, the will that has become an object in the intuitive mind. The will and representation constitute the essence of reality. The human being cannot visualize the will clearly without the body. And the emotions and the inner world are implicated in the process. This unity (of will and body) has a special nature that cannot be accounted for by the four semantic categories of logical, empirical, metaphysical, and metalogical truth. It is not a relationship among abstract representations, but a judgment on the relationship between an intuitive representation, the body, and that which is not representation at all, but something different from it toto genere (in all things), namely, the will. Schopenhauer calls this philosophical truth kat'exochen (par excellence). We can say that the will is the a priori knowledge of the body and that the body is the a posteriori knowledge of the will. For this reason, we can argue, along with Bacon, Kepler, and Leibniz, that inorganic nature too has will. The entire body, in all its natural properties, is a phenomenological manifestation of the will. Inorganic nature is a phenomenon of that will. But in what way? We can speak of the life within every material thing in the sense that it possesses internal forces in the same way a living organism does. In the metaphysics of nature these forces (magnetism, electricity, heat, crystallization, mechanics, gravity, movement, etc.) pertaining to the manifestation of bodies and matter, connect back to the will and are powerfully analogous to the phenomena of life. These forces stem from an inner essence of the bodies, and the will is perceived as an authentic thing in-itself, in the absence of a purpose and a limit (every end attained is but the beginning of a new process into infinity) in an eternal becoming that reveals itself. The only knowledge the will has of itself in general is representation as a whole, that is to say, the totality of the intuitive world. This fact constitutes its objectivity and its revelatory nature. 
We have, therefore, come to understand, accepting the will as illuminating knowledge, the world itself as a living sculpture behind which we find Goethe's "formative force".

Giorgio Agamben [8] has critiqued the Kantian definition of the beautiful as disinterested pleasure, taking as his starting point the third essay in On the Genealogy of Morals, where Friedrich Nietzsche points out how Immanuel Kant [9] avoids the aesthetic problem of the artist, the creator, and the artwork, preferring to reflect on beauty and art, and he looks at the spectacle of the beautiful through the eyes of the spectator. As opposed to Kant, Agamben argues that, for Stendhal, beauty can appear as promesse de bonheur (the promise of happiness). Returning to Nietzsche, whose views are consonant with Agamben's position, the experience of art described with words is not aesthetics; in other words, it is not a purification from sensibility filtered through the concept; on the contrary, it can be described as the expression of the will to power. The spectator yields, indeed must yield, his place to the creative artist. In this regard, we are invited by Agamben to recall the myth of Pygmalion. The sculptor's imagination is so excited by the sight of his work that he wishes it could come alive and not merely remain a work of art. This story of the overlapping and the splitting of reality and form takes us back to Plato, as we have seen, and even further back to Sophocles' Antigone as regards the use of technical skill to produce an object and to make its image available for use.

$\mathrm{We}$, therefore, note a sort dual aspect of art: that which is experienced by the spectator and that which is experienced by the artist. We see all this especially with the birth of the man of taste in the seventeenth century. For Agamben, there is a loss of artistic and creative essence the moment we reflect on the art object and produce collections and museums. The duality of art has an effect on art itself, giving rise to contrasting variations on the principle of aesthetic value, which in its very distortion, i.e., Kitsch and ugliness, acquires features that are interesting for some people even if those features are not consonant with an initial response and assessment. Beauty is, therefore, subject to an evaluative unease whose power Denis Diderot notes in Rameau's Nephew and whose contradictoriness Georg W.F. Hegel acknowledges in The Phenomenology of the Spirit.

In the chapter on the dissolution of Romantic art in his Lezioni di estetica [Lectures on aesthetics] [10] (pp. 674-676), Hegel feels the need to put in a historical framework the question of the unity of the artist and both his external material and the culture to which he or she belongs. At the same time, he points out that the destiny of Western art can be understood only in the context of the radical splitting described above. Hegel argues that, as long as he or she remains tied to a general and religious conception, the artist truly accepts that content together with its representation, and he experiences them in a tangible way. This content is the truth and the infinity of his or her consciousness: matter and substance are within the artist, who gives them the form of representation. From Romanticism onward, the development of critical thought, like freedom of expression, "became obsessed with the artist" turning art into a free instrument at the disposal of the artist, who can manipulate any content according to his or her subjective preferences. Every material, therefore, can be treated indifferently. Anything can be beautiful, that is, capable of being treated artistically. Referring to the society of his day, Hegel said that there is no material that can escape this relativity.

Agamben [8] goes on to say that the original unity of the artwork was split into aesthetic judgment and artistic subjectivity. He asserts that we have a universe with no content, pure creativity. Romantic art and the art that came after undergo this process whereby the unity and the identity of subject and object dissolves. Faced with Kant's four necessary conditions of beauty as the object of aesthetic judgment (disinterested pleasure, universality not based on concepts, purposiveness without purpose, and subjective necessity), we cannot resist citing Nietzsche's countervailing thought in Twilight of the Idols [11] where, against metaphysics, he asserts that the clear signs of nonbeing or nothingness are the true essence of things. In aesthetic judgment, then, the beautiful does not appear really to reside in its status as art object, but in what it appears to be, in other words, in what it is not, namely, non-art. In aesthetic judgment, the authenticity of a form of shadowy presence that has become the absolute value of aisthesis dies. The living reality of the creator-artist is replaced by the transcendence of the spectator. For Agamben [8] (p. 75), modern and contemporary art is conscious of its own shadow and sees in it its own negation; and, closing the gap between it and the critics, it becomes itself the logos of art and its shadow, that is, art criticism. 
Today we find a general tendency to focus on the truth of the artwork, which is supposed to consist in the creative and formal act considered independently of the content. Given the decline of the aura, instigated by the new media and the avant-gardes, we are asked to locate the most fertile roots of the artistic praxis, of poiesis, and consider the possibility of going beyond the prevailing kitsch. There is a desire to fold the contemplated image into poetic motion, beyond the critical threshold of the transcendence of the spectator. Today, the truth of the artwork should reside in the concrete play of forms independently of ideas. This is what Federico Vercellone [12] believes, following the suggestion by Hans Belting [13] in the face of the widespread homologation, and he identifies the anthropological need for form in which beauty regains full meaning in the world. But, since the canons and the original, creative forms of reception and enjoyment have disappeared, how does the image, beyond the object and beyond the frayed contours and the indefiniteness of content, work in the resignification offered by visual studies? This is the open field of the current situation after postmodernism. The image is increasingly the release of the symbolic energy, the going beyond the concept, as well as the power of the gaze that envelops both the subject and the object. Its nature is not merely the capacity to copy but possibly to reveal.

Hans Belting proposes a critical anthropology of the image that focuses not only on the primacy of the art, but on the analysis of the triad of image, medium, and body, as well. The medium is the material; the image is the event, and the body is the form. In the course of its technical evolution, the image exists in the spectrum of the new virtual reality and applications, where the mobile holographic image occupies a special place. In the Anthropocene epoch, it can generate unimaginable relationships between living entities and things. Vast material forms will soon be confused with their mobile holographic reproductions in vivo. Light will soon create roads, bridges, cities, and territories resulting in cognitive upheavals. Icons fired into the ether will be much more powerful than the virtual reality of our cellphones. What is the value of experience when confronted with an artwork reproduced in a mobile holograph? What is at stake for a philosophy of representation? A desire for omnipotence propels the quest for domination that enslaves. This is the image of the third millennium and we need to understand what representation is in order to come up with possible approaches to the new mythologies.

Representation is tied to perception, memory, and function. It is not mere reproduction; rather, it is an active process that entails anticipation, learning, and cognitive development. It involves a symbolic play among invention, expression, and imitation.

Representation has many facets, as we can clearly see in Edmund Husserl [5,6] and in Ludwig Wittgenstein [14]. The activities of reflecting, imitating, presenting, presentifying, simulating, impressing, expressing, and imagining all revolve around some aspects of context: the representation takes the place of the represented; the representation draws from within itself its representability; the representation describes the represented; the representation is the mirror image of the represented; the represented is represented through the representation; the representation represents itself via a cognitive apparatus; and the representation is a creation of the subject. In essence, we know that there is more than a network of correspondences between the elements of a representation and that which is represented inasmuch as it depends on the form of the representation and its capacity to stimulate associations in the mind, language, and communication. We have been saying this since Plato along the lines of the pedagogy of "typical" images, according to Wunenburger [1].

To return now to the aesthetic and artistic question, images present themselves with a degree of ambiguity that can also be read as a degree of effectiveness. The object is even more interesting when we consider the metaphor of the mirror and the space of the fantastic. Roger Caillois [15] saw the fantastic as something different from the surprising and the unexpected we find in fables and myths. Its identity and authenticity derive from the way the object is treated by the subject and by the breaking of the conventions that historically have characterized its interpretation. According to Caillois, the fantastic object reveals a hidden treasure that enchants us and a mystery that captivates us. This is due to the fact that we can see emerging from the undefinable and secret signs, both on a deep level and on the surface, a grand and charming awe. Alongside this view, the universe explored by Jurgis Baltrušaitis [16-19] conveys a "heart of wonders", the part of our doing and imaging that is 
most alive and emotional-a panoply of extraordinary things - rather than an exaltation of the fantastic. The interpretation he offers, however, touches upon, and sometimes overlaps with, aspects of the fantastic identified by Caillois [15], in particular where we attempt to access what is hidden, or arcane, beyond the institution of forms and the canons of connotative and historical classification. Baltrušaitis [16-19] does not aim to describe a particular aesthetic knowledge or a particular creative intelligence as much as to shed light on humanity's special memory, a series of signs and traces that have a related identity, which is very important but often misunderstood. This memory is produced by a reading of allegorical oddities, visual and emotional dissonances, unusual iconological analogies, unanticipated genealogies, and the pleasure of the hybrid. There is a certain similarity between Caillois and Baltrušaitis as regards these issues.

The engine of the system of symbols and emblems that underpins this memory produces an "excellence of the ambiguous", which has already been mentioned. This phrase refers to the organicity of an overturned convention, the full legitimacy of a collection of unusual and unsettling beauties, ignored by humans in recent history, beauties that, nonetheless, suit them. With his works, Baltrušaitis has composed a true "celebration of wonderment" [18]. Brilliant craftsmanship manifests itself in a delirium of the unusual and the unreal that has always characterized the tempestuous passion of humans: catoptric chambers, machines that transform men into animals, globes of fire, prodigious auras, multiple suns, apparitions, doublings, aberrant perspectives, changing physiognomies, painted stones, wild Gothic visions, and mysterious hieroglyphs. The power and excellence of things admired stems from a reappraisal of an "alchemical alphabet", since the figures examined express something more than the fact that they are simple illustrations, mere descriptions of elements and givens. Comparing art and nature, Baltrušaitis formulates a cosmological theory based on the study of the forms of representation. By temporal coincidence, "archetypes of the imagination" emerge in different cultures and traditions throughout the world. The celebration of wonderment, thus, provides a network of recurring primordial images in which we see reflected the collective unconscious. Geometric designs, vegetation, roots, minerals, celestial devices are swept up in an "ontology of the deformed". In the search for features common to various models, there is an emphasis on the represented object, the genius of which does not properly reside in the intention of the artist or in the subject of the artwork or allegory, but between the two. It is the genius of the transition and transformation directed at creating a world of extreme delights; this is a light, speedy, and powerful spirit capable of creating an entire morphology of change, a daemon of invention that conjures up alchemical paradigms. Artists and spectators discover one another in an aesthetic rapture that, at the same time, harmoniously reveals and transforms nature, by both perfecting and deforming it, like a break-down of light and a blurring of contours. The relationships between the exact sciences and the imagination in its pure state are re-established. The analogy predominates; here it is a "monstrous" hermeneutics with a rich array of images. It also concerns itself with legend and myth, for example, that of Isis because such a search for myth is similar to an "aberration", as Baltrušaitis [19] himself argued. The search gives rise to a saga of forms and is comparable to the optical distortion called "anamorphosis". Hence we proceed, through various fields of knowledge and Egyptian theogonies, to arrive at another point in distorted perspectives in an effort to uncover metaphysical truths, truths tied to the esoteric and alchemical universe, imaginary truths.

The web of relationships applies not only to the fantastic, but to the domains of seeing and appearing as well: of reality, illusion, and invention. Bernard Lassus [20] has shown this by identifying the transformation of the object in the landscape when forms elude perception. Perceiving and imagining are engaged in an aesthetic play of mimesis and simulation, exchange and transformation. The "natural" image, like the one mechanically reproduced, is the staging of the world.

The cluster of wonders offered up by Baltrušaitis $[16,18,19]$ is the result of a light, airy but unsettling navigation that depicts the reverse side of the sky, the other side of beauty. Referencing Réveils et prodigies [Awakenings and prodigies], Caillois [15] underscores the fact that Baltrušaitis, in examining the image of the Apocalypse, removes it from the biblical text. The image was depicted in a long, much admired cycle extending from the Cologne Bible edited by Heinrich Quintel (1498) to the frescoes on Mount Athos in the seventeenth century, and passing through Albrecht Dürer (1498) 
and Jean Duvet (1561) in the process. Caillois [15] claims that, by doing so, Baltrušaitis, wanted to offer up a solitary and stimulating "rêverie" on the process of translation from one art form to another, spanning an evocative distance, and suggesting a flow of magical transformations, between literature and painting, between word and image. Thus, the meaning of the text changes through its iconographic depictions in a haze of aesthetic motifs. This confirms the idea, previously discussed, of the creative flight as the epitome of a "marvelous system of forms". These elements too, which are associated with dreams and the oneiric, enigma and the bizarre, being expressions of the mind, belong essentially to a theory of the iconic act as developed by Horst Bredekamp [21], who draws a distinction among artifice, the interaction between the body and representation, and the power of the imaginative form in an intermediate work of "plastic semantics" in the context of the perennial contrast between matter and spirit.

We also find the question of beauty and harmony closely connected to that of the representation of nature and the nature of representation. If we wanted to talk of a possible harmony in Western thought and aesthetics, we could consider the meaning that harmony has in the functioning of the faculties. In his Critique of Judgment, Kant [9] bases the universality of aesthetic judgments not on some sort of cosmic harmony, but on the common workings of the faculty of judgment. This subjective assessment of the object or its representation precedes the pleasure of the object itself. In this sense, this is absolutely not harmony among the parts of the object, but it brings to bear the imagination, which exists in the faculties and in the transcendental way in which the faculties operate. It is in the faculties that we come to understand the materiality and transformation of nature, as well as its essence: the subject and object participate in a process of reciprocal actions. In some ways, harmony suffers the same fate as beauty with which it is so intimately joined. Both tend to fade in the modern aesthetic vocabulary because they imply "a metaphysical ambiguity".

In essence, from the reflections and examples provided here, we cannot think of the image without a philosophy of representation.

Conflicts of Interest: The authors declare no conflict of interest.

\section{References}

1. Wunenburger, J.J. Lo specchio delle immagini. Gerarchia e traduzione delle rappresentazioni in Platone. Estetica Studi Ricerche 2013, 1, 47-57.

2. Sartre, J.P. L'Imagination; Alcan: Paris, France, 1936.

3. Sartre, J.P. Structure intentionelle de l'image. Revue de Métaphysique et de Morale 1938, XLV, 543-609

4. Sartre, J.P. The Imaginary: A Phenomenological Psychology of the Imagination; Einaudi: Turin, Italy, 2007.

5. Husserl, E. Cartesian Meditations; Costa, F., Ed.; Bompiani: Milan, Italy, 1968.

6. Husserl, E. Ideas for a Pure Phenomenology and a Philosophical Phenomenology; Filippini, E., Ed.; Einaudi: Turin, Italy, 1965.

7. Schopenhauer, A. Metaphysics of Nature; Volpicelli, I., Ed.; Laterza: Bari, Italy, 2017.

8. Agamben, G. The Man without Content; Quodlibet: Macerata, Italy, 1994.

9. Kant, I. Critique of Judgment; Hafner: New York, NY, USA, 1964.

10. Hegel, G.W.F. Aesthetics; Merker, N., Ed.; Einaudi: Turin, Italy, 1967.

11. Nietzsche, F. Twilight of the idols. In Opere (Complete Works); Colli, G., Montinari, M., Eds.; Adelphi: Milan, Italy, 1986; Volume VI, pp. 51-163.

12. Vercellone, F. After the Death of Art; Il Mulino: Bologna, Italy, 2013.

13. Belting, H. The Canons of the Gaze. History of Visual Culture in the Orient and the West; Bollati Boringhieri: Turin, Italy, 2010.

14. Wittgenstein, L. The Tractatus and Notes 1014-1916; Conte, A.G., Ed.; Einaudi: Turin, Italy, 1997.

15. Caillois, R. In the Heart of the Fantastic; Feltrinelli: Milan, Italy, 2010.

16. Baltrušaitis, J. The Medieval Fantastic. Antiquity and Exoticism in Medieval Art; Adelphi: Milan, Italy, 1973.

17. Baltrušaitis, J. Anamorphosis or the Artificial Magic of Marvelous Effects; Adelphi: Milan, Italy, 1978

18. Baltrušaitis, J. Seeking Isis. An essay on the Legend of a Myth; Adelphi: Milan, Italy, 1985.

19. Baltrušaitis, J. Awakenings and Prodigies: An Essay on the Metamorphosis of the Gothic; Adelphi: Milan, Italy, 1999. 
20. Lassus, B. The Landscape Approach; University of Pennsylvania Press: Philadelphia, PA, USA, 1998.

21. Bredekamp, H. Images that Look back. A Theory of the Iconic Act; Raffaello Cortina: Milan, Italy, 2015.

(C) 2017 by the authors. Licensee MDPI, Basel, Switzerland. This article is an open access article distributed under the terms and conditions of the Creative Commons Attribution (CC BY) license (http://creativecommons.org/licenses/by/4.0/). 